\title{
Quality of Nursing Documentation and its Effect on Continuity of patients' care
}

\author{
Ahmed I. Abd El Rahman', Manal M. Ibrahim²\& Gehan M. Diab ${ }^{3}$ \\ ${ }^{1}$ B.Sc. Nursing Science, ${ }^{23}$ Professor of Nursing Administration, Faculty of Nursing, \\ Menoufia University
}

\begin{abstract}
Background: Nursing documentation is defined as the record of nursing care that is planned and given to individual patients and clients by qualified nurses or other caregivers under the control of a qualified nurse. Purpose of the study: Assess the relation between quality of nursing documentation system and the continuity of patient care at Tanta university hospitals. Study design: Descriptive correlational design was utilized to conduct this study. Study setting: The study was conducted at Tanta University Hospitals affiliated to Ministry of Health. Study sample: A convenient sample of 80 nurse supervisors and simple random sample of 80 staff nurses in intensive care units. Data collection instruments: Data was collected using two instruments adapted by the investigator. The first instrument was a quality of nursing documentation questionnaires. The second instrument was Auditing continuity of patient care checklist. Results: The present study showed that the most of studied samples resulted in accepted level of nursing documentation quality and the majority of total studied samples resulted in average level of continuity of patient care. Conclusion: There was a highly statistically significant positive correlation between quality of nursing documentation and continuity of patient care. Recommendations: Encourage nurses to comply with standard of nursing documentation at intensive care units.
\end{abstract}

Keywords: Continuity of patients' care- Quality of nursing documentation - Intensive care units.

\section{Introduction}

Nursing documentation is defined as the record of nursing care that is planned and given to individual patients and clients by qualified nurses or other caregivers under the control of a qualified nurse. In addition, nursing documentation can be used for specific purposes such as quality assurance. Despite continuous and consistent advice from quality-improvement programs and professional bodies over several years, achieving and maintaining good standards of clinical documentation is still a problem in the health profession (Alkouri, AlKhatib and Kawafhah, 2016).

Nursing documentation is an essential function of professional nursing practice (Hariyati, Yani, Eryando, Hasibuan and Milanti, 2016). The documentation should be factual, current, and comprehensive to provide consistent information about the assessment, care provided, and evaluation of patient responses to care (Perry, Potter and Ostendorf, 2019). Current health care systems require that documentation ensure continuity of care, provide legal evidence of 
nursing care provided, and support evaluation of quality patient care. To enhance patient outcomes that include patient safety, accurate and complete clinical information is required as a valid and reliable source to be used for communication, quality improvements, research and policymaking (Akhu-Zaheya, Alloubani and Awwad, 2018).

Documentation of the nursing care is important for continuity of care, communication between nurses and other professionals, as well as the legal aspect of care (Petrakaki, Klecun and Cornford, 2016). Documentation is important to provide quality and safe nursing care to patients. Furthermore, nursing documentation also serves as the indicator of the service quality, evidence of responsibility and accountability of nurses, and database for research purpose or evidence-based policymaking (Palmer, Marengoni, Forjaz, Jureviciene, Laatikainen, Mammarella and Onder, 2018).

Some essential characteristics of quality information in patient records include completeness and comprehensiveness. Nursing documentation based on the nursing process facilitates effective care as patient's needs can be traced from assessment and nurses are empowered in clinical decision-making. Criteria for effective or quality documentation include use of common vocabulary, legible writing, use of authorized abbreviations and symbols (Liu, Galik, Boltz, Nahm, Lerner and Resnick, 2016). Quality criteria of nursing documentation includes completeness, quantity, legibility, patient identification, chronological report of events, comprehensiveness of description, nursing assessment, objective information, signature, date and timeliness (Doenges, Moorhouse and Murr,2016).

High quality of nursing documentation aims to promote structured, consistent and effective communication between caregivers, and facilitate continuity of care and patient safety. Inadequate communication between caregivers is associated with discontinuity of care, a factor that contributes to errors. The consequences of discontinuity of care are linked to increased cost and length of hospital stay, readmissions, poorer patient satisfaction, adverse events, delays in treatment and diagnosis, inappropriate treatment and omission of care (Petersen, Marais, Abdulmalik, Ahuja, Alem, Chisholm and Thornicroft, 2017).

In order to ensure continuity of care, Nurses are obligated by law to document care provided in the patient record, as well as exchange relevant and necessary information. This obviously also includes passing information across health care settings during patient transfer. The requirements for in what way the information should be exchanged differ, however, depending on what kind of health care setting the patient is transferred from. While transfer from institutions, such as hospitals and nursing homes, requires a written (or electronically) summary of the patient record, the act does not have any requirements for in what form the information should be provided by the 
home health care ((Dang and Dearholt, 2017).

\section{Significance of the study:}

Despite numerous research studies which have focused on quality nursing documentation. The relationship between quality of nursing documentation and continuity of patient care has received far less attention in literature. Few studies which looked at this topic have noted that quality of nursing documentation system is associated with better continuity in patient care. It was found during training experience that there were problems in documentation in university hospitals as inaccurate, inappropriate, incomplete and disorganized charts or records. The records could not be reliable in clinical decision or incomplete patient care for medical and nursing personnel. Therefore, in the current study, the investigator will spot the light on the relationship between quality of nursing documentation system and continuity of patient care at university hospitals.

\section{Purpose of the study:}

The purpose of the current study is to assess the relation between quality of nursing documentation system and the continuity of patient care at Tanta university hospitals through the following research questions:

1- What is the quality of current nursing documentation at Tanta university hospitals?

2- What is the current level of continuity of patients' care at Tanta university hospitals?
3- What is the relation between quality of nursing documentation and continuity of patient care?

\section{Methods:}

\section{1- Research Design:}

A descriptive correlational design was utilized to conduct this study.

\section{2- Study Setting:}

The present study was conducted at Tanta University Hospitals affiliated to Ministry of Health. These hospitals including The Main University Hospital (1000 bed) included orthopedic, medical, pediatric, general surgery, obstetric, neonates, urology, chest and cardiology, intensive care units (ICU), neuropsychiatric, dehydration treatment unit and plastic surgery. The Student Hospital (166beds) included renal dialysis, medical department, chest and openheart operation (OR), ICUs and general ward. The Ophthalmology Hospital (65beds) included: Ear, Nose, Throat (ENT) and ophthalmic departments. The Emergency Hospital (275 beds) included neurosurgery, medical, surgery, recovery, poisoning, burn, orthopedic departments and ICU.

\section{3- Study Sample:}

Two groups of subjects were used on the current study:

1. Convenient sample of nurse supervisors (80 nurse supervisor) are used in the time of data collection which included in this study as following: (35) in the Main University Hospital, (25) Nurse Supervisors in Mubarak Hospital, (14) Nurse Supervisors in 
Emergency Hospital and (6) Nurse Supervisors in Ophthalmology Hospital.

2. Simple random sample of staff nurses who give direct patient care and use records, and reports in ICU units at the university hospitals. Using the Slovin's formula to calculate the 2nd subjects' group (Tejada, 2012).

\section{4- Instruments for data collection:}

- Data were collected by using the following two instruments.

First Instrument: "Quality of nursing documentation questionnaires. It was adapted from Afify, Awad and Abd el Wahab (2003). This instrument aimed to assess the quality of nursing documentation from nurse supervisors' point of view. It is consisted of two parts: First part: demographic data of nurse supervisors as gender, years of experience, educational level, residence, and job position. Second part: It covered (10) dimensions with 78 items as follow: types of nursing records formats availability (15 items), the reasons of unavailability of formats (3 items), types of nursing records formats kept in patient's file after patient discharge (15 items), responsibilities of reviewing recorded nursing format (3items), standards of nursing documentation quality (14 items), attendance of training programs related to nursing documentation(3 items), factors lead to poor documentation (8 items), importance of nursing documentation quality (8items), importance of continuity of patient care from nurse's point of view (6items) and responsibility of writing shift report (3 items).

The scoring system of Instrument one:

\begin{tabular}{|c|c|c|}
\hline Dimension & $\begin{array}{c}\text { Number of } \\
\text { items }\end{array}$ & Scale \\
\hline Types of nursing formats availability & 15 items & $\begin{array}{l}\text { 1. Available and use (2). } \\
\text { 2. Available but not used (1). } \\
\text { 3. Unavailable (0). }\end{array}$ \\
\hline $\begin{array}{l}\text { 1. Reason of unavailability of format. } \\
\text { 2. Types of nursing record formats kept in patient file } \\
\text { after patient discharge. } \\
\text { 3. Responsibilities of reviewing recorded nursing } \\
\text { formats. } \\
\text { 4. Standard of nursing documentation quality. } \\
\text { 5. Attendance of training programs related to nursing } \\
\text { documentation. } \\
\text { 6. Factors lead to poor documentation. }\end{array}$ & $\begin{array}{l}\text { 3Items } \\
15 \text { items } \\
3 \text { items } \\
14 \text { items } \\
3 \text { items } \\
8 \text { items }\end{array}$ & $\begin{array}{l}\text { A. yes (1). } \\
\text { B. No (0). }\end{array}$ \\
\hline $\begin{array}{l}\text { 1. Importance of nursing documentation quality. } \\
\text { 2. Importance of continuity of patient care. } \\
\text { 3. Responsibility of writing shift report. }\end{array}$ & $\begin{array}{l}8 \text { items } \\
6 \text { items } \\
3 \text { items }\end{array}$ & $\begin{array}{l}\text { A.Strongly agree (4). } \\
\text { B.Agree (3). } \\
\text { C.Disagree (2). } \\
\text { D.Strongly disagree (1). } \\
\text { E.Do not know (0). }\end{array}$ \\
\hline
\end{tabular}

The total score for this entire instrument is 144. The quality of nursing documentation was estimated at level :> 60\% Accepted level of nursing documentation $=(66)$ score or more and $<60 \%$ Unaccepted level of 
nursing documentation=below score.

Second Instrument: Auditing continuity of patient care checklist. The aim of this instruments to assess continuity of patient care by auditing checklist (observational checklist).It was Adapted from Abdo, Bashaier, Mohamed El Sayed (2014).It covered (6) dimensions with 29 items as follow: giving medication (2items: complete and incomplete medication order), vital signs (4 items; T, P, R and Bp), fluid balance (4 items; intravenous, Ryle, urine and drainage), laboratory investigations (4 items; ordering, implementing, sending and resulting), nursing intervention (9 items) and shift report (6 items).

\section{Scoring system:}

Observed continuity of patient care was checked against (5) points Likert scale as follow: Done and recorded (4), done but not recorded (3), not done but recorded (2), not applicable (1) and not done and not recorded (0) respectively. The total score was (116) scores. The levels for continuity of patient care as follow:

1) Cut point level of continuity of patient care $=(58 \%)$.

2) Low continuity of care from 0 to $<58$ scores.

3) Average Continuity of care from 58 to $<87$ scores.

4) High Continuity of care from $>87$ to 116 scores.

\section{Validity of the instruments:}

Validity of two instruments were assessed using content validity by five experts (3 experts from Menoufia University and 2 experts from Tanta University) in nursing administration department at nursing faculties. The relevance, clarity, fluency and simplicity of each component in the two instruments was examined by experts and they found that the two instruments are useful and helpful according to the objectives of the research.

Necessary modification was done and unnecessary questions were deleted to reach the final valid version of the instruments which considered valid from the expert's perspective.

\section{Reliability of the instruments:}

The instruments were tested to reliability by the Cronbach's alpha. Reliability was estimated among 10\% related participants for each questionnaire by using test-retest method with two weeks apart between them. Then correlation coefficient was calculated between two scores. Correlation coefficient was 0.84 for questionnaire, 0.83 for checklist of continuity of patient care.

\section{Pilot study:}

The investigator conducted a pilot study before administering final questionnaire. The purpose of pilot study was to ascertain clarity, relevance, applicability, sequence of the study instruments and to determine obstacles that may be encountered during data collection. It also helped to estimate time required to fill the questionnaire sheets. The pilot study was carried out on $(10 \%)$ of subjects $(8$ 
nurse supervisors), also they were excluded from the main study subjects to fill out the questionnaire. Based on the results of pilot study, rephrasing of some questions was done to ensure clarity of questions and to be easily understood by nurse supervisors. The time required for each nurse supervisor to fill the questionnaires was estimated to be 15-20 minutes.

\section{Data collection procedure:}

Before beginning to collect data from the study sample the investigator introduce himself to them, explained the aim of the study and informed them that their information was treated confidential and used only for purpose of the research. Additionally, each participant was notified about right to accept or refuse to participate in the study. Data was collected in the morning and afternoon shift and subject response to questions in the presence of investigator to ascertain that all questions were answered. Data was collected upon four months started from January 2020 to April 2020.

Continuity of patient care was done through using observational checklist to observe all hospital staff tasks and activities through done or not done. Data were collected by the investigator for each staff nurse three times in three different days per week, and total higher frequency of either done or not done was taken as a final data collection for each time of each task.

\section{Ethical consideration:}

Before any attempt to collect data, written approval letter was submitted to director of Tanta University
Hospital. The letter contains the title, aim of the study and method of data collection. Data collection procedures, analysis and reporting of finding were undertaken in a manner designed to protect confidentiality of subjects. The study was conducted with careful attention to ethical standards of research and rights of the participants. The ethical committee at faculty of nursing, Menoufia University revised study protocol and accepts the topic as they assured this study did not violate the rights of participants. The sample rights were protected by ensuring voluntary participation. So that informed consent was obtained by explaining purpose, nature, time of conducting study, potential benefits of the study and how data will be collected.

The subjects were assured that the data will be treated as strictly confidential. Furthermore, the respondents' anonymity was maintained, as they were not required to mention their names.

\section{Statistical design:}

The collected data were organized, tabulated and statistically analyzed using SPSS software statistical computer package version 22 and Epiinfo program. For quantitative data, the range, mean and standard deviation were calculated. For qualitative data, comparison was done using Chi-square test $\left(\chi^{2}\right)$.

Correlation between variables was evaluated using Pearson and Spearman's correlation coefficient $r$ and Fisher Exact test. A significance 
was adopted at $\mathrm{P}<0.05$ for interpretation of results of tests of significance (*). Also, a highly significance was adopted at $\mathrm{P}<0.01$ for interpretation of results of tests of significance

\section{Results:}

Table (1): Socio-demographic characteristics of the studied subjects (nurses and patients):

\begin{tabular}{|c|c|c|}
\hline \multirow{2}{*}{ Characteristics } & \multicolumn{2}{|c|}{$\begin{array}{c}\text { The studied nurses } \\
(n=145)\end{array}$} \\
\hline & $\mathbf{N}$ & $\%$ \\
\hline $\begin{array}{cl}\text { Age (in years): (nurses) } \\
\text { : } & 20-30 \\
: & 30-40 \\
\text { : } & \text { Mean } \pm \text { SD }\end{array}$ & $\begin{array}{l}98 \\
42 \\
20\end{array}$ & $\begin{array}{c}61.25 \\
26.25 \\
12.5 \\
32.7 \pm 5.22\end{array}$ \\
\hline $\begin{aligned} & \text { Gender: } \\
& \text {. } \text { Male } \\
& \text { Female }\end{aligned}$ & $\begin{array}{c}30 \\
130\end{array}$ & $\begin{array}{l}18.8 \\
81.2\end{array}$ \\
\hline \begin{tabular}{|cl} 
Marital status: \\
& Married \\
. & Unmarried \\
\end{tabular} & $\begin{array}{c}120 \\
40\end{array}$ & $\begin{array}{l}75 \\
25 \\
\end{array}$ \\
\hline 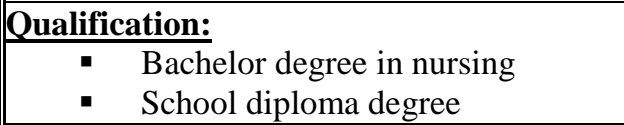 & $\begin{array}{l}80 \\
80\end{array}$ & $\begin{array}{l}50 \\
50 \\
\end{array}$ \\
\hline 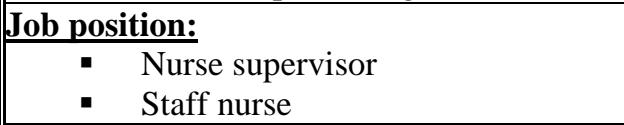 & $\begin{array}{l}80 \\
80\end{array}$ & $\begin{array}{l}50 \\
50 \\
\end{array}$ \\
\hline \begin{tabular}{|rl} 
Years of experience: \\
$:$ & $<5$ \\
$:$ & $5-<10$ \\
$:$ & $10-20$ \\
$:$ & Mean \pm SD \\
\end{tabular} & $\begin{array}{l}12 \\
96 \\
52\end{array}$ & $\begin{array}{c}7.50 \\
60 \\
32.5 \\
10.0 \pm 5.34\end{array}$ \\
\hline 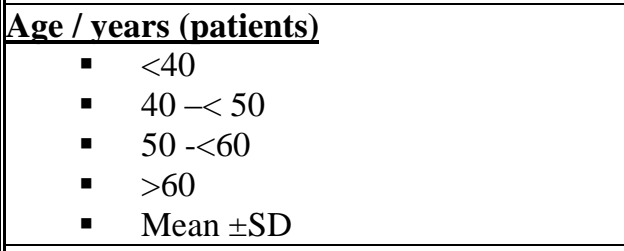 & $\begin{array}{l}10 \\
15 \\
40 \\
15\end{array}$ & $\begin{array}{c}12.5 \\
18.75 \\
50 \\
18.75 \\
50.2 \pm 13.0 \\
\end{array}$ \\
\hline \begin{tabular}{|ll} 
Gender & \\
: & Male \\
. & Female \\
\end{tabular} & $\begin{array}{c}8 \\
72 \\
\end{array}$ & $\begin{array}{l}10.0 \\
90.0\end{array}$ \\
\hline \begin{tabular}{|ll} 
Units & \\
- & Anesthesia ICU \\
- & Emergency ICU \\
& Medical ICU
\end{tabular} & $\begin{array}{l}40 \\
20 \\
20\end{array}$ & $\begin{array}{l}50 \\
25 \\
25\end{array}$ \\
\hline
\end{tabular}

This table clarified that, according to the age of studied nurses, the nearly two third of studied nurses ranged from 20 to 30 years $(61.25 \%)$. Concerning their gender, the majority of studied nurses were female (81.2\%).
Regarding their marital status, the majority of studied nurses were married $(75 \%)$. In relation to their qualification, the half of studied nurses (50\%) had a bachelor degree in nursing. Concerning their job position, 
the half of studied nurses were nurse supervisor (50\%). Regarding years of experience, the nearly two third of studied nurses' years of experience (60\%) ranged from 5 to 10 years with Mean $\pm \mathrm{SD}=(10.0 \pm 5.34)$. while concerning age of studied patients, the half of studied patients aged from 50 to
$<60$ years $(50 \%)$. According to their gender, the most of the studied patients were female (90\%). Regarding the types of units that the studied patients were admitted in, the half of studied patients were admitted in anesthesia intensive care unit (50\%).

Table (2): Percentage distribution of nursing records formats type's availability as reported by nurse supervisors $(n=80)$ :

\begin{tabular}{|l|c|c|c|c|c|c||}
\hline \multirow{2}{*}{$\begin{array}{l}\text { Types of nursing records formats } \\
\text { availability }\end{array}$} & \multicolumn{2}{|c|}{$\begin{array}{c}\text { Available and } \\
\text { used }\end{array}$} & \multicolumn{2}{c|}{$\begin{array}{c}\text { Available but } \\
\text { not used }\end{array}$} & \multicolumn{2}{c|}{ Not available } \\
\cline { 2 - 7 } & No. & $\%$ & No & \% & No. & \multicolumn{2}{c|}{} \\
\hline Nursing notes & 80 & 100 & 0 & 0.00 & 0 & 0.00 \\
\hline Changing position of patient format & 68 & 85.0 & 6 & 7.50 & 6 & 7.50 \\
\hline Medication administration sheet & 80 & 100 & 0 & 0.00 & 0 & 0.00 \\
\hline Fluid balance sheet & 80 & 100 & 0 & 0.00 & 0 & 0.00 \\
\hline Handover form & 80 & 100 & 0 & 0.00 & 0 & 0.00 \\
\hline Patient assessment form on admission & 80 & 100 & 0 & 0.00 & 0 & 0.00 \\
\hline Nursing care plan form & 80 & 100 & 0 & 0.00 & 0 & 0.00 \\
\hline Discharge planning form & 80 & 100 & 0 & 0.00 & 0 & 0.00 \\
\hline Insulin administration form & 68 & 85.0 & 0 & 0.00 & 12 & 15.0 \\
\hline Heparin administration form & 19 & 23.8 & 8 & 10.0 & 53 & 66.2 \\
\hline Vital signs sheet & 80 & 100 & 0 & 0.00 & 0 & 0.00 \\
\hline Informed consent form & 80 & 100 & 0 & 0.00 & 0 & 0.00 \\
\hline Progress note sheet & 68 & 85.0 & 0 & 0.00 & 12 & 15.0 \\
\hline Incident report sheet & 12 & 15.0 & 0 & 0.00 & 68 & 85.0 \\
\hline Pain assessment form & 73 & 91.3 & 0 & 0.00 & 7 & 8.70 \\
\hline
\end{tabular}

This table clarified that all nursing notes, medication administration sheets, fluid balance sheets, handover forms, patient assessment forms on admission, nursing care plan forms, discharge planning forms, vital signs sheets and informed consent forms were available and used (100\%).As indicated in this table, the highest percentage of nurse supervisors reported that changing position of patient formats., insulin administration forms, progress note sheets and pain assessment forms were available and used ( $85 \%$ and $91.3 \%$ respectively). While the least percentage of nurse supervisors reported that heparin administration forms and incident report sheets were available and used (23.8\% and $15 \%$ respectively).

Table (3): Percentage distribution of staff nurse's attendance of training programs related to nursing documentation and factors lead to poor documentation as reported by nurse supervisors $(\mathrm{n}=80)$ : 


\begin{tabular}{||l|c|c|c|c|}
\hline \multirow{2}{*}{ Items } & \multicolumn{2}{|c|}{ Yes } & \multicolumn{2}{c|}{ No } \\
\cline { 2 - 5 } & No. & $\%$ & No. & \% \\
\hline Staff nurse's attendance of training programs related to nursing documentation \\
\hline In the unit & 74 & 92.5 & 6 & 7.50 \\
\hline In the hospital & 52 & 65.0 & 28 & 35.0 \\
\hline Outside the hospital & 13 & 16.3 & 67 & 83.7 \\
\hline Factors lead to poor documentation & \multicolumn{4}{|c|}{} \\
\hline Lack of good monitoring system & 30 & 37.5 & 50 & 62.5 \\
\hline Lack of understanding of coding & 59 & 73.8 & 21 & 26.2 \\
\hline Leaving banks on forms & 37 & 46.2 & 43 & 53.8 \\
\hline Not dating, timing and signing entries & 43 & 53.8 & 37 & 46.2 \\
\hline Use of inappropriate abbreviations & 77 & 58.8 & 33 & 41.2 \\
\hline Entering information into wrong chart & 41 & 51.2 & 39 & 48.8 \\
\hline Documentation takes long time & 80 & 100 & 0 & 0.00 \\
\hline Nursing shortage & 40 & 50.0 & 40 & 50.0 \\
\hline
\end{tabular}

This table showed that, concerning staff nurse's attendance of training programs, the highest percentage of staff nurses $(92.5 \%)$ were attended training programs related to nursing documentation in the unit. While the majority of staff nurses $(83.7 \%)$ did not attend training, programs related to nursing documentation outside the hospital. Regarding to factors which lead to poor documentation, the half of the nurse supervisors agreed on not dating, timing and signing entries, entering information into wrong chart and nursing shortage as factors lead to poor documentation $(50 \%, 51.2 \%$ and $53.8 \%$ respectively). Also, the majority of nurse supervisors $(73.8 \%)$ agreed on lack of understanding of coding as a factor lead to poor documentation. On the other side, the two third of the nurse supervisors $(62.5 \%)$ did not agree on lack of good monitoring system as a factor lead to poor documentation. Finally, all nurse supervisors (100\%) agreed on documentation took a long time as a factor lead to poor documentation.

Table (4): Total quality of nursing documentation at university hospitals

\begin{tabular}{|c|c|c|}
\hline Studied variable & No. & $\%$ \\
\hline $\begin{array}{l}\text { Total quality of documentation } \\
\text { Accepted level of nursing documentation } \\
\text { Un accepted level of nursing documentation }\end{array}$ & $\begin{array}{c}75 \\
5\end{array}$ & $\begin{array}{l}93.7 \\
6.30\end{array}$ \\
\hline $\begin{array}{l}\text { Total quality of documentation } \\
\text { Mean } \pm \text { SD } \\
\text { Min - Max }\end{array}$ & \multicolumn{2}{|c|}{$\begin{array}{c}114.6 \pm 6.14 \\
87-123\end{array}$} \\
\hline
\end{tabular}

This table shows that the most of studied samples resulted in accepted level of nursing documentation quality

$(93.7 \%)$. 
Quality of Nursing Documentation and its Effect on Continuity of patients' care

Table (5): Percentage distribution of auditing continuity of patient care related to nursing intervention, vital signs and laboratory investigation $(n=80)$ :

\begin{tabular}{|c|c|c|c|c|c|c|c|c|c|c|}
\hline \multirow[t]{2}{*}{ 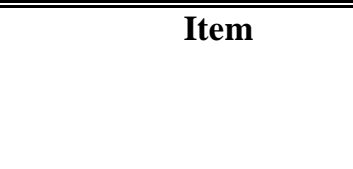 } & \multicolumn{2}{|c|}{$\begin{array}{l}\text { Done and } \\
\text { recorded }\end{array}$} & \multicolumn{2}{|c|}{$\begin{array}{c}\text { Done and } \\
\text { not } \\
\text { recorded }\end{array}$} & \multicolumn{2}{|c|}{$\begin{array}{l}\text { Not done } \\
\text { but } \\
\text { recorded }\end{array}$} & \multicolumn{2}{|c|}{$\begin{array}{c}\text { Not } \\
\text { applicable }\end{array}$} & \multicolumn{2}{|c|}{$\begin{array}{c}\text { Not done, } \\
\text { not } \\
\text { recorded }\end{array}$} \\
\hline & No. & $\%$ & No. & $\%$ & No. & $\%$ & No. & $\%$ & No. & $\%$ \\
\hline \multicolumn{11}{|l|}{ Vital signs } \\
\hline \multicolumn{11}{|l|}{ Morning shift } \\
\hline - $\quad$ Temperature & 80 & 100 & 0 & 0.00 & 0 & 0.00 & 0 & 0.00 & 0 & 0.00 \\
\hline - Pulse & 80 & 100 & 0 & 0.00 & 0 & 0.00 & 0 & 0.00 & 0 & 0.00 \\
\hline $\begin{array}{ll} & \text { Respiration } \\
\end{array}$ & 80 & 100 & 0 & 0.00 & 0 & 0.00 & 0 & 0.00 & 0 & 0.00 \\
\hline - $\quad$ Blood pressure & 80 & 100 & 0 & 0.00 & 0 & 0.00 & 0 & 0.00 & 0 & 0.00 \\
\hline \multicolumn{11}{|l|}{ Evening shift } \\
\hline $\begin{array}{ll}- & \text { Temperature }\end{array}$ & 64 & 80.0 & 0 & 0.00 & 16 & 20.0 & 0 & 0.00 & 0 & 0.00 \\
\hline - Pulse & 64 & 80.0 & 0 & 0.00 & 16 & 20.0 & 0 & 0.00 & 0 & 0.00 \\
\hline - $\quad$ Respiration & 64 & 80.0 & 0 & 0.00 & 16 & 20.0 & 0 & 0.00 & 0 & 0.00 \\
\hline - $\quad$ Blood pressure & 64 & 80.0 & 0 & 0.00 & 16 & 20.0 & 0 & 0.00 & 0 & 0.00 \\
\hline \multicolumn{11}{|l|}{ Night shift } \\
\hline - $\quad$ Temperature & 72 & 90.0 & 8 & 10.0 & 0 & 0.00 & 0 & 0.00 & 0 & 0.00 \\
\hline - Pulse & 72 & 90.0 & 8 & 10.0 & 0 & 0.00 & 0 & 0.00 & 0 & 0.00 \\
\hline - $\quad$ Respiration & 72 & 90.0 & 8 & 10.0 & 0 & 0.00 & 0 & 0.00 & 0 & 0.00 \\
\hline - $\quad$ Blood pressure & 72 & 90.0 & 8 & 10.0 & 0 & 0.00 & 0 & 0.00 & 0 & 0.00 \\
\hline \multicolumn{11}{|l|}{ Lab. Investigations } \\
\hline A) Ordering & 80 & 100 & 0 & 0.00 & 0 & 0.00 & 0 & 0.00 & 0 & 0.00 \\
\hline B) Implementing & 80 & 100 & 0 & 0.00 & 0 & 0.00 & 0 & 0.00 & 0 & 0.00 \\
\hline C) Sending & 72 & 90.0 & 8 & 10.0 & 0 & 0.00 & 0 & 0.00 & 0 & 0.00 \\
\hline D) Resulting & 80 & 100 & 0 & 0.00 & 0 & 0.00 & 0 & 0.00 & 0 & 0.00 \\
\hline \multicolumn{11}{|l|}{ Nursing intervention } \\
\hline Care of tubes & 48 & 60.0 & 16 & 20.0 & 8 & 10.0 & 0 & 0.00 & 8 & 10.0 \\
\hline Hygienic care & 40 & 50.0 & 8 & 10.0 & 32 & 40.0 & 0 & 0.00 & 0 & 0.00 \\
\hline Patients exercises & 40 & 50.0 & 16 & 20.0 & 16 & 20.0 & 0 & 0.00 & 8 & 10.0 \\
\hline Health education & 40 & 50.0 & 8 & 10.0 & 16 & 20.0 & 0 & 0.00 & 16 & 20.0 \\
\hline Nursing observation & 40 & 50.0 & 8 & 10.0 & 16 & 20.0 & 0 & 0.00 & 16 & 20.0 \\
\hline Changing position & 16 & 20.0 & 40 & 50.0 & 16 & 20.0 & 0 & 0.00 & 8 & 10.0 \\
\hline Glasgow coma scale & 16 & 20.0 & 24 & 30.0 & 8 & 10.0 & 0 & 0.00 & 32 & 40.0 \\
\hline $\begin{array}{l}\text { Physical, psychological } \\
\text { assessment }\end{array}$ & 40 & 50.0 & 8 & 10.0 & 16 & 20.0 & 0 & 0.00 & 16 & 20.0 \\
\hline Patient complaints & 48 & 60.0 & 16 & 20.0 & 8 & 10.0 & 0 & 0.00 & 8 & 10.0 \\
\hline
\end{tabular}

This table highlights percentage distribution of auditing continuity of patient care related to vital signs, laboratory investigation and nursing intervention. Concerning vital signs, at morning shift, all vital signs were done and recorded in all studied sample $(100 \%)$. At evening shift, all vital signs were done and recorded only in the majority of total studied sample $(80 \%)$. At night shift, all vital signs were done and recorded only in the most of total 
studied sample (90\%). Regarding to lab. investigation, ordering, implementing and resulting of lab. investigation were done and recorded in all studied samples (100\%) but sending results of lab. investigation were done and recorded in the most of total studied samples (90\%). In relation to nursing intervention, care of tubes and patient complaints were doing and recorded in the near two third of total studied samples (60\%). While hygienic care, patient exercises, nursing observation, physical, psychological assessment and health education were doing and recorded in the half of total studied sample (50\%).On the other side, changing position of patient was doing and not recorded in the half of total studied samples (50\%).

Table (6): Frequency distribution of total continuity of care at university hospitals

\begin{tabular}{|l|c|c|}
\hline Studied variable & No. & $\%$ \\
\hline Continuity of patient care & 80.0 \\
Average & 64 & 20.0 \\
High & 16 & \\
\hline Continuity of patient care & \multicolumn{2}{|c|}{} \\
Mean SD & \multicolumn{2}{|c|}{$87.0 \pm 5.39$} \\
Min - Max & \multicolumn{2}{|c|}{82} \\
\hline
\end{tabular}

This table shows that the majority of total studied samples resulted in average level of continuity of patient care $(80 \%)$.

Table (7): Correlation between quality of Nursing documentation and continuity of patient care:

\begin{tabular}{|l|c|c|}
\hline \multirow{2}{*}{ Studied variable } & \multicolumn{2}{|c|}{ Quality of documentation } \\
\cline { 2 - 3 } & $\mathbf{r}$ & P value \\
\hline Continuity of patient care & 0.434 & $0.001^{* *}$ \\
\hline
\end{tabular}

This table clarified that there was highly statistically significant positive correlation between quality of nursing documentation and continuity of patient care $(\mathrm{r}=0.434-\mathrm{p}$ value $=0.001)$. 


\section{Discussion:}

Nursing documentation provides an important indicator of the quality of care provided for hospitalized patients. Nursing documentation has been defined as the record of nursing care that is planned and given to individual patients and clients by qualified nurses or by other caregivers under the direction of a qualified nurse (Alkouri et al., 2016).In general, most of the literature does not deal with behaviors and communication skills between the nurse-patient relationship and the role of both. There has been a large amount of documentation on selfcare strategies, medication adherence, psychological interventions, and patient and nurse satisfaction (Molin and Gallo, 2020).

Therefore, the present study was carried out to assess the relation between quality of nursing documentation system and the continuity of patient care in university hospitals. Before discussing the study results related to these research questions, light should be directed toward the socio-demographic characteristics of the study participants who were presented into two groups. The first group included a sample of the studied nurses (160) who were working at the previously mentioned study settings and the second group included a sample of critically ill patients (80), supervised by the studied nurses in the same study settings.

In relation to the studied nurses, the results of the present study clarified that the highest percent of nurses in the study sample were at age ranges from 20 to 30 years and nearly two third of the study sample has $(5-<10)$ years of experience. Concerning their job position, the half of studied nurses were nurse supervisor. Regarding educational level, about half of the study sample nurses had bachelor degree in nursing. Furthermore, in relation to gender and marital status, the majority of the studied nurses were female and married.

The present study revealed that the most of studied samples resulted in accepted level of nursing documentation quality. This result provides the answer of the first research question of the present study. In agreement with the present study result, the study of Molin and Gallo, (2020) showed that the majority of studied samples resulted in accepted level of nursing documentation quality. It is believed that the quality of nursing documentation plays very important roles in encouraging structured, consistent and effective communication between caregivers and facilitates continuity and individuality of care and safety of patients.

The present study result also was congruent with the study of Lindo et al., (2016) in which the results showed that the most of studied samples resulted in accepted level of nursing documentation quality. The complex task of nursing documentation is often guided by the nursing process, a framework for solving patient care problems, and ensuring the provision of high-quality nursing care. Furthermore, this result was supported 
by results of Molina-Mula et al., (2018) which revealed that the majority of studied samples resulted in accepted level of nursing documentation quality.

On the other hand, two studies of Taiye (2015) and Nakate et al., (2014)were contradicting to the present study result as the results reported that the two third of studied samples resulted in unaccepted level of nursing documentation quality.

From the investigator's point of view, the present study result, the reason for good levels of nurses' knowledge about documentation in hospitals may be due to the educational nature of those hospitals as the continuing education was a recently followed strategy in the last years. In addition, better educational facilities, more inservice training programs, and organizing of educational processes are considered factors that enhance a better competence level. It was observed also that the study nurses were trained on the quality of performance standards of their units as the patients on these units need special care

The current study showed that, concerning the total continuity of patient care, the majority of total studied samples resulted in average level of continuity of patient care. This result provides the answer of the second research question of the present study. In agreement with the present study result, the study of Mendes et al., (2017) showed that the majority of total studied samples resulted in average continuity of patient care. In order to develop strategies for continuity of care, health organizations must establish different organizational mechanisms, including: training, planning and decision making at the inter-institutional level through information systems, interdisciplinary clinical evaluation, protocols, followup and professional feedback.

The present study result also was congruent with the study of Mirlashari et al., (2016) in which the results showed that most of total studied samples resulted in average continuity of patient care. It illustrated that employing interested and competent nurses and considering the standards required in the Neonatal Intensive Care Units can increase the quality of care in those wards. Also, the study of Nilsson et al., (2016) which supported our study result, clarified that the majority of total studied samples resulted in average continuity of patient care. It showed that the professional documentation of nursing is crucial importance for high quality care and patient related outcomes.

Finally, the other studies of Hassan, (2018) and Thabet et al., (2019) supported the present study result as they showed that the majority of total studied samples resulted in average level of continuity of patient care.

On the other hand, two studies of Bowen, et al. , (2015) and Palmer, et al. , (2018) contradicting the present study result as the results reported that the majority of total studied samples resulted in low level of continuity of patient care and showed that several factors can adversely affect continuity of patient care. Physicians who establish good rapport with consumers 
are more likely to retain patrons, and in effect maintain continuity of service. Conversely, physicians who do not build good rapport might lose patients regularly, disrupting continuity of service due to consumers seeking new care providers. In fact, patient satisfaction has historically influenced continuity of care and vice versa.

From the investigator's point of view, this result may be because an observation checklist, instead of a questionnaire, was used to assess the level of continuity of patient care that related directly to patient care and as the majority of the studied patients in that was presented to those patients through assessing the presented care and nurses' activities.

The present study result showed that there is a highly statistically significant positive correlation between quality of nursing documentation and continuity of patient care at Intensive Care Units. This result provided the answer of the third research question of the present study. The result of Nobahar, (2016) agreed with the present study result as it showed that having good level of nursing documentation leads to an improved quality of patient care and an increased patient satisfaction with the nurses and helps promote nursing as a profession and improve nursing education and clinical nursing. Therefore, it illustrated that there is a highly statistically significant positive correlation between quality of nursing documentation and continuity of patient care.

The present study result also was congruent with the study of Schober,
(2016) in which the results showed that the level of quality of nursing documentation directly affects the continuity care of patients and there is a highly statistically significant positive correlation between quality of nursing documentation and continuity of patient care. Furthermore, this result was supported by results of Dang and Dearholt, (2017) which revealed that there is a highly statistically significant positive correlation between quality of nursing documentation and continuity of patient care.

Additionally, other studies of Marie, et al., (2016) and Hariyati et al., (2016) supported the present study result as they showed that there is a highly statistically significant positive correlation between quality of nursing documentation and continuity of patient care. Our study was also in line with Petresen, et al., (2017) who reported that there is a highly statistically significant positive correlation between quality of nursing documentation and continuity of patient care. Besides, another study of Maarsingh, et al., (2016) was consistent with the present study result as it showed that that there is a highly statistically significant positive correlation between quality of nursing documentation and continuity of patient care.

From the investigator's point of view, High quality nursing documentation aims to promote structured, consistent and effective communication between caregivers, and facilitate continuity of care and patient safety. Inadequate communication between caregivers is associated with discontinuity of care, a 
factor that contributes to errors. The consequences of discontinuity of care are linked to increased cost and length of hospital stay, readmissions, poorer patient satisfaction, adverse events, delays in treatment and diagnosis, inappropriate treatment and omission of care.

Finally, the present study results showed that the highest percentage of nurses in the study sample were at age ranges from 20 to 30 years, the half of studied nurses were nurse supervisor, the majority of the studied nurses were female and married, the most of studied samples resulted in accepted level of nursing documentation quality $(93.7 \%)$, the majority of total studied samples resulted in average level of continuity of patient care $(80 \%)$ and there is a highly statistically significant positive correlation between quality of nursing documentation and continuity of patient care at Intensive Care Units $(\mathrm{r}=0.434 \mathrm{-p}$ value $=0.001)$.

\section{Conclusion}

The present study was carried out to investigate the relation between quality of nursing documentation system and the continuity of patient care in university hospitals. All nurses of university Hospitals agreed about importance of quality of nursing documentation and continuity of patient care, the most of studied samples resulted in accepted level of nursing documentation quality, the majority of total studied samples resulted in average level of continuity of patient care. Finally, this study emphasized that there is a highly statistically significant positive correlation between quality of nursing documentation and continuity of patient care.

\section{Recommendations}

Based on the findings of the present study, the following recommendations were suggested:

- Holding workshop with the staff about importance of nursing documentation and documentation standard\& principles.

- Encourage nurses to comply with standard of nursing documentation at intensive care units.

- Apply nursing documentation policies to guide nurse's performance.

- Continuous supervision of nursing documentation through regular and periodic auditing is suggested, with constructive feedback, as well as disciplinary actions for defaulters and rewards for good achievers.

- The hospital administration should address the barriers to adequate nursing documentation identified by the nurses, and provide all needed resources.

- Provide opportunities to attend national and international nursing conferences to improve their knowledge about nursing documentation principles and importance.

- Further research is proposed to assess the impact of on-the-job training and application of electronic health records on nurses' practices in documentation. 
- Replication of the study on large sample size and different settings.

\section{References:}

Akhu Zaheya, L., Al Maaitah, R., \& Bany Hani, S. (2018). Quality of nursing documentation: Paper based health records versus electronic based health records. Journal of clinical nursing, 27(3-4), e578-e589.

Alkouri, O. A., AlKhatib, A. J., \& Kawafhah, M. (2016). Importance and implementation of nursing documentation: review study. European Scientific Journal, 12(3).

Ammenwerth, E., Rauchegger, F., Ehlers, F., Hirsch, B., \& Schaubmayr, C. (2011). Effect of a nursing information system on the quality of information processing in nursing: An evaluation study using the HISmonitor instrument. International journal of medical informatics, 80(1), 25-38.

Dang, D., \& Dearholt, S. L. (2017). Johns Hopkins nursing evidence-based practice: Model and guidelines. Sigma Theta Tau.

Dehghan, M., Dehghan, D., Sheikhrabori, A., Sadeghi, M., \& Jalalian, M. (2013). Quality improvement in clinical documentation: does clinical governance work? Journal of multidisciplinary healthcare, 6 , 441.
Geurden, B., Wouters, C., Franck, E., Weyler, J., \& Ysebaert, D. (2013). Does documentation in nursing records of nutritional screening on admission to hospital reflect the use of evidence-based practice guidelines for malnutrition? International journal of nursing knowledge, 25(1), 43-48.

Hariyati, R. T. S., Yani, A., Eryando, T., Hasibuan, Z., \& Milanti, A. (2016). The effectiveness and efficiency of nursing care documentation using the SIMPRO model. International journal of nursing knowledge, 27(3), 136-142.

Hassan, N. A. (2018). Assessing Nurses' Knowledge and Auditing their Practices Regarding Nursing Care Documentation. Port Said Scientific Journal of Nursing, 5(1), 95-112.

Instefjord, M. H., Aasekjær, K., Espehaug, B., \& Graverholt, B. (2014). Assessment of quality in psychiatric nursing documentation-a clinical audit. BMC nursing, 13(1), 32.

Jefferies, D., Johnson, M., Nicholls, D., \& Lad, S. (2012). A wardbased writing coach program to improve the quality of nursing documentation. Nurse education today, 32(6), 647651.

Kamil, H., Rachmah, R., \& Wardani, E. (2018). What is the 
problem with nursing documentation? Perspective of Indonesian nurses. International journal of Africa nursing sciences, 9, 111-114.

Lindo, J., Stennett, R., Stephenson Wilson, K., Barrett, K. A., Bunnaman, D., Anderson Johnson, P., \& Wint, Y. (2016). An audit of nursing documentation at three public hospitals in Jamaica. Journal of Nursing Scholarship, 48(5), 499-507.

Maarsingh, O. R., Henry, Y., van de Ven, P. M., \&Deeg, D. J. (2016). Continuity of care in primary care and association with survival in older people: a 17-year prospective cohort study. British Journal of General Practice, 66(649), e531-e539.

Marie, T., \& Jaroslav, P. (2016). Provision of Nursing Care with or without Therapeutic Communication Intervention. US-China L. Rev., 13, 75.

Mendes, F. R. P., Gemito, M. L. G. P., Caldeira, E. D. C., Serra, I. D. C., \& Casas-Novas, M. V. (2017). Continuity of care from the perspective of users. Ciencia\&saudecoletiva, 22 , 841-853.

Mirlashari J., Qommi R., Nariman S., Bahrani N. \& Begjani J., (2016). Clinical Competence and Its Related Factors of Nurses in Neonatal Intensive
Care Units. Journal of Caring Sciences, 2016, 5(4), 317-324.

Molina-Mula, J., \& Gallo-Estrada, J. (2020). Impact of nursepatient relationship on quality of care and patient autonomy in decision-making. International journal of environmental research and public health, 17(3), 835 .

Molina-Mula, J., Gallo-Estrada, J., \& Perelló-Campaner, C. (2018). Impact of Interprofessional Relationships from Nurses' Perspective on the Decision-Making Capacity of Patients in a Clinical Setting. International journal of environmental research and public health, 15(1), 49.

Nilsson J., Gardulf A. \& Lepp M., (2016). Process of translation and adaptation of the Nurse Professional Competence (NPC) Scale. Journal of Nursing Education and Practice 2016, Vol. 6, No. 1 EXPERIENCE EXCHANGE

Nobahar, M., (2016). Competence of nurses in the intensive cardiac care unit, May 2016, Volume: 8, Issue: 5, Pages: 2395-2404,

DOI: http://dx.doi.org/10.19082/23 $\underline{95}$

Ofi, B., \& Sowunmi, O. (2012). Nursing documentation: Experience of the use of the nursing process model in selected hospitals in Ibadan, Oyo State, Nigeria. 
International journal of nursing practice, 18(4), 354-362.

Okaisu, E. M., Kalikwani, F., Wanyana, G., \& Coetzee, M. (2014). Improving the quality of nursing documentation: An action research project. curationis, 37(2), 1-11.

Olsen, R., Hellzén, O., Skotnes, L., \& Enmarker, I. (2014). Breakdown in informational continuity of care during hospitalization of older homeliving patients: A case study. International journal of integrated care, 14(2).

Petersen, J. A., Rasmussen, L. S., \& Rydahl-Hansen, S. (2017). Barriers and facilitating factors related to use of early warning score among acute care nurses: a qualitative study. BMC emergency medicine, 17(1), 19.

Schober, M. (2016). Introduction to advanced nursing practice. Springer International Publishing.174. DOI 10.1007/978-3-319-32204-9.
Scruth, E. A. (2014). Quality nursing documentation in the medical record. Clinical nurse specialist, 28(6), 312-314.

Thabet, O., Ghanem, H., Ahmed, A. \& Abd-ElMouhsen, S., (2019). Effect of Developing and Implementing Nursing Care Standards on outcome of Patients Undergoing Cardiac Catheterization. IOSR Journal of Nursing and Health Science (IOSR-JNHS), vol. 8, no. 01, 2019, pp. 42-54.

Thoroddsen, A., Sigurjonsdottir, G., Ehnofors, M., \& Ehrenberg, A. (2013) Accuracy completeness and comprehensiveness of information on pressure ulcers recordedin the patient record. Scandinavian Journal of Caring Science, 27, 84-91.

Wang, N., Hailey, D., \& Yu, P. (2011). Quality of nursing documentation and approaches to its evaluation: a mixed method systematic review. Journal of advanced nursing, 67(9), 1858-1875. 